Discussion Paper No. 843

\title{
PROMOTION WITHOUT COMMITMENT: SIGNALING, TIME INCONSISTENCY AND DECENTRALIZATION OF THE FIRM
}

Junichiro Ishida

May 2012

The Institute of Social and Economic Research Osaka University

6-1 Mihogaoka, Ibaraki, Osaka 567-0047, Japan 


\title{
Promotion without Commitment: Signaling, Time Inconsistency and Decentralization of the Firm*
}

\author{
Junichiro Ishida \\ ISER, Osaka University
}

May 10, 2012

\begin{abstract}
This paper explores the consequences and implications of the "dual role of promotion" in an environment where a firm must simultaneously achieve two distinct goals assignment and incentive provision - via the strategic use of promotions. We argue that the efficient promotion rule is generally not implementable, as it necessarily entails timeinconsistent objectives: the firm is always tempted ex post to promote the worker with the highest upside potential rather than the one with the highest output. This ex post bias towards the assignment role of promotion leads to inefficient task choices where too many workers are induced to work on the difficult task to signal their productivities. The framework identifies the costs and benefits of decentralization, in relation to factors such as the levels of human and social capital, the degree of market competition, firm size, and distance to the technology frontier, and provides predictions that are in line with recent empirical evidence.
\end{abstract}

JEL Classification Codes: D82, M51.

Key Words: Assignment, Incentive provision, Tournament, Promotion, Commitment, Time inconsistency.

${ }^{*}$ Correspondence to: Junichiro Ishida, Institute of Social and Economic Research, Osaka University, 6-1 Mihogaoka, Ibaraki, Osaka 567-0047, Japan. E-mail: jishida@iser.osaka-u.ac.jp. 


\section{Introduction}

Promotion decisions are one of the most important decisions to be made within firm organizations. There are mainly two reasons for this. First, since positions higher up in a firm's hierarchy tend to assume a larger degree of authority and responsibility, promotions almost inevitably function as an assignment mechanism of internal human resources. Second, promotions can also be a reward for workers, either directly or indirectly, and hence provide an important strategic device for incentive provision. This latter aspect is particularly important when performance measures are not verifiable, though observable, so that a firm cannot enforce complete contracts contingent on those measures. In the absence of complete wage contracts, a firm may be forced to use promotions not only to assign but also to motivate its workers.

In this paper, we explore the consequences and implications of this "dual role of promotion" in an environment where assignment cannot be separated from incentive provision due to contractual incompleteness. We argue that the efficient promotion rule is generally not implementable in such an environment, unless the firm possesses full commitment power, because the efficient rule inherently entails time-inconsistent objectives: incentive provision typically calls for a promotion rule which selects the worker with the highest output (who has contributed most in the past) whereas assignment calls for a rule which selects the worker with the highest upside potential (who is expected to contribute most in the future). A conflict between assignment and incentive provision then naturally arises when the worker with the highest output differs from the one with the highest upside potential. The problem is that, whenever the conflict surfaces, it is typically resolved in favor of the assignment role, as the firm is always tempted ex post to promote the worker with the highest upside potential rather than the one with the highest output. This ex post bias towards the assignment role severely limits the value of promotion as an incentive device and distorts workers' behavior, which yields a wide array of implications for organizational design.

We illustrate this problem though a simple tournament model in which a firm hires $n$ workers who compete for a promotion. Each worker differs in innate ability which is his own private information. The key aspect of the model is that there are two distinct ways to produce output, which we call tasks for expositional clarity, where one is standardized and more labor-intensive (the easy task) while the other is less conventional and more ability- 
intensive (the difficult task). The difficult task is more productive only if the worker's ability is sufficiently high, and we assume that there exists an ability threshold above which the difficult task is more productive. The firm's goal in this setup is to devise a promotion rule which provides proper incentives for each worker to choose the right task (incentive provision) and still allows the firm to identify and select the most deserving worker (assignment).

Even though the firm is in a situation that it must "kill two birds with one stone," the solution to this problem is actually very simply, at least conceptually, if the firm can credibly enforce a complete promotion rule. With full commitment power, the firm can realize the allocation which maximizes total output by simply promising to promote the worker with the highest output, as this promotion rule makes each worker's objective aligned squarely with the firm's objective of profit (output) maximization. ${ }^{1}$ The problem is that this rule, though simple and clear, is not enforceable when the firm lacks the ability to commit to a contingent promotion rule ex ante because it is not sequentially rational to abide by this rule once the task choices have been made. Anticipating this, the workers' attention naturally diverges away from the firm's objective of profit maximization, and consequently distorts their task choices.

In this setup, we first show that, in the absence of full commitment, it is always the case that too many workers opt for the difficult task in equilibrium compared to the firstbest efficiency level. ${ }^{2}$ The logic behind this result is as follows. Since the productivity is more sensitive to the worker's ability, the difficult task generates a more accurate signal of unobservable ability. Conversely, since the easy task is a noisier signal, those workers who choose the easy task are more or less "pooled" from the firm's viewpoint. If the firm evaluates its workers based purely on the perceived ability type, a worker who is just below the firstbest efficiency threshold always has an incentive to deviate and switch to the difficult task to signal his ability. This distortion in task choice lowers the firm's overall productivity as too many workers work on the task that is actually too difficult for them to carry out. ${ }^{3}$

The tension between the two roles of promotion, as illustrated here, yields a range of implications for the optimal design of organization, especially the optimal degree of decen-

\footnotetext{
${ }^{1}$ In the present setup, as we will describe later, the firm and the workers simply split the total output with some exogenous share, so that profit maximization is equivalent to output maximization.

${ }^{2}$ The first-best allocation is defined as the one which maximizes total output. See section 3.1 where we provide formal definitions of efficiency criteria in this model.

${ }^{3}$ In a broad sense, this may be regarded as a form of influence activity because workers attempt to convey information for private benefits at the expense of low productivity.
} 
tralization (delegation of decision rights). Given that the root of the problem lies in the fact that there are more than one way to produce output, a potential (second-best) solution is to limit the workers' job discretion altogether and force them to follow the standardized way of production. The cost of centralization in this context is then obvious: by limiting the extent of job discretion and virtually forbidding its workers to experiment with new, potentially more innovative, ways of production, the firm effectively wastes opportunities to solicit and utilize their private information. Despite this apparent cost, the firm might still choose to centralize when the output loss from distorted task choices outweighs the cost. Analyzing this tradeoff explicitly, our framework clarifies the costs and benefits of decentralization, in relation to factors such as the levels of human and social capital, the degree of market competition, firm size and distance to the technology frontier. We later discuss in greater depth how those results can be interpreted in light of recent empirical findings on firm organization.

Identifying the determinants of decentralization also yields an implication of broader interest, as it sheds light on one of the long-standing issues in economics. The literature on firm productivity reveals that there exists an astonishingly large productivity dispersion across firms and countries, even within narrowly defined sectors, a large portion of which is left unexplained by observable factors. While this still remains largely a puzzle, two observations are suggestive on this account: first, there is a set of management practices, such as decentralization, effective monitoring, well-defined targets and incentives, that are generally associated with high productivity; ${ }^{4}$ second, there is also a substantial variation in the quality of management practices across firms as well as countries. These observations have led to an argument that the difference in the quality of management practices can account for a large fraction of the large productivity dispersion across business units (Bloom and Van Reenen, 2007, 2010; Bloom et al., 2010). In this paper, we shed light on this problem by clarifying the costs and benefits of decentralization and show, for instance, why it is not optimal for some firms to decentralize despite all the potential benefits or why low-productivity firms appear to be trapped with bad management practices.

The paper is related to several distinct strands of literature. First, it is related to works which analyze the role of signaling via task choices (or promotions decisions) in organizations

\footnotetext{
${ }^{4}$ See Bloom and Van Reenen $(2007,2011)$ for an association between productivity and human resource management (HRM). Although these observations, which are based on cross-sectional data, do not necessarily indicate the causational relationship, Bloom et al. (2011) run a randomized experiment and find that the lack of delegation results in inefficient decision making and reallocation of resources.
} 
and the distortions it causes. The most notable along this line is Waldman (1984) who considers promotion as a signal. ${ }^{5}$ In this model and many other models of asymmetric learning, a worker's productivity is observable to the firm (the current employer) but not to the market (outside employers). ${ }^{6}$ Assuming that promotion decisions are observable to the market, it is then shown that the firm has incentives to distort task assignments in order to exploit the value of private information. Ishida (2006) considers a different setup where promotion also serves as a signal, but the uninformed party in that model is the worker who makes an inference about his own productivity through promotion decisions. The current work belongs to this strand of literature in that task choices convey information. The difference is that the informed party in our model is the workers who signal their productivities though task choices to the firm. ${ }^{7}$

Although the two roles of promotion have been well recognized in the literature, ${ }^{8}$ few works have explicitly focused on the potential conflict between them in a single framework. ${ }^{9}$ One of few exceptions is Waldman (2003) who analyzes the time-inconsistency problem arising from the two conflicting roles of promotion. The source of time inconsistency in his model is the possibility of external hiring, where a firm can fill a position by hiring an outsider. He then shows that there are circumstances in which the firm is made better off by committing to not hiring from outside, thereby giving a rationale for the common practice of internal promotions. A key difference from this work is that time inconsistency in our model arises because there are different ways to produce output, and the output alone is not necessarily the best indicator of a worker's qualifications. We then focus on the workers' signaling incentives and the distortion caused by them, in order to further inquire into the potential consequences and implications of the dual role of promotion which, in our own view, have not been explored

\footnotetext{
${ }^{5}$ The possibility of asymmetric learning can also provide a possible explanation for why firms often ties wages to ranks.

${ }^{6}$ Models of asymmetric learning include Ricart i Costa (1988), Bernhardt (1995), Ishida (2004), Owan (2004) and Limor (2005) among others.

${ }^{7}$ It is also important to note that the meaning of "task choice" differs critically between those previous models and the current one. In Waldman (1984) and others, a worker is said to be promoted when he is assigned to a more difficult task. Here, task choices are totally independent of promotion decisions, as they simply refer to different ways to proceed the job at hand.

${ }^{8}$ See, for instance, Gibbons and Waldman (1999a) for a survey.

${ }^{9}$ The two roles of promotion have largely been analyzed separately. For instance, Gibbons and Waldman (1999b, 2006) provide a model of job assignment, combined with human capital accumulation and learning, that can capture a wide range of stylized facts. In these works, however, they sidestep the issue of incentive provision. Similarly, works which take promotion as the incentive mechanism, such as the theory of tournament by Lazear and Rosen (1981) and others, typically do not consider the issue of assignment.
} 
fully yet.

The paper is also related to the large and diverse literature which examines the allocation of authority within the firm. Many studies depict decentralization as a means to solicit private information that cannot be observed directly by the principal. Aghion and Tirole (1997) analyze the impact of the allocation of authority on the incentive to acquire information with particular focus on the distinction between real and formal authority. Dessein (2002) considers cheap talk communication in organizations, and shows that decentralization emerges as the optimal choice as long as the incentive conflict is not too large. ${ }^{10}$ Acemoglu et al. (2007) examine a situation where a firm must decide whether to adopt a new technology and argue that the firm delegates control to the manager when the value of local information is high. The current paper shares this view that an important virtue of decentralization is to utilize the agent's private information more effectively but approaches from an alternative perspective which rests on the time-inconsistent nature of the efficient promotion rule. Moreover, while the cost of decentralization in all of the works mentioned above originates from the agent's preference bias that is exogenously given, it stems from the lack of commitment on the principal's part in our model, which yields some implications of practical importance.

Finally, the paper also intends to contribute to the literature on tournament. The current model introduces a new dimension to the problem by incorporating a task choice problem into a tournament setting. This addition gives rise to strategic interactions between the principal and the agents - an aspect which is absent in the canonical tournament model, such as Lazer and Rosen (1981), where the principal is virtually depicted as an impartial observer - which allows us to shed light on a new type of inefficiency that could arise in this type of setup. ${ }^{11}$ This aspect is illuminated most clearly when we extend the baseline model to include effort choices: in the extended version of the model, we show that there arises a novel tradeoff between effort and task choices where an increase in rewards induces higher effort at the expense of more distorted task choices.

The paper is organized as follows. In section 2, we briefly outline the baseline model. Section 3 analyzes the model, characterizes the equilibrium and provides some comparative

\footnotetext{
${ }^{10}$ There are now several works which employ cheap talk to analyze the optimal extent of decentralization. For instance, Alonso and Matouschek (2007) incorporate cheap talk communication and show that threshold delegation is optimal for a wide range of circumstances when the principal has some commitment power.

${ }^{11}$ The previous literature focuses on types of inefficiency which arise from strategic interactions among agents. One prominent example is the possibility of sabotage where the agents may exert effort to reduce the rivals' outputs. See Lazear (1989), Chen (2003) and Ishida (2012) along this line of works.
} 
statics exercises. Section 4 discusses the model's implications, especially in relation to the existing empirical evidence. Section 5 presents an extension of the baseline model where effort choices are also endogenized. Finally, section 6 offers concluding remarks.

\section{The baseline model: exogenous promotion bonus}

Setup: There are a firm (principal) and $n$ workers (agent), denoted by $i=1,2, \ldots, n$, who compete for a promotion. Each worker $i$ is characterized by his ability type, denoted by $\eta_{i} \in$ $[0,1]$, which is distributed according to $F$ with full support over $[0,1]$. Let $\mu(\eta):=\frac{\int_{0}^{\eta} \eta^{\prime} d F\left(\eta^{\prime}\right)}{F(\eta)}$ and $\mu:=\mu(1)$. The ability type of a worker is his private information which cannot be observed by the firm.

Task choice and job discretion: Let $y_{i} \in[0,1]$ denote worker $i$ 's output level. There are two tasks, easy (task $E$ ) and difficult (task $D$ ), and each worker must perform either one. There are established and clearly defined procedures for task $E$ where a worker can produce output simply by exploiting the stock of existing knowledge. The productivity in task $E$ is hence less sensitive to the worker's ability. In contrast, there are no established procedures for task $D$ where a worker needs to explore new ideas on how to proceed the task. Since task $D$ inevitably tests the worker's creativity, the productivity depends more on his ability. To capture this difference in the nature of the tasks, we specify that

$$
y_{i}= \begin{cases}\theta & \text { if worker } i \text { works on task } E \\ \eta_{i} & \text { if worker } i \text { works on task } D\end{cases}
$$

where $\theta \in(0,1)$ is some constant which measures the current state of existing knowledge.

At the beginning, the firm determines whether to delegate task choice decisions to its workers or not. If the firm chooses to delegate (the case of decentralization), each worker is allowed to choose whichever the task he prefers at his own discretion. We assume that the workers make their decisions simultaneously and independently under decentralization. If the firm chooses not to (the case of centralization), on the other hand, it retains full authority over the task allocation and orders all the workers to work on task $E .^{12}$

\footnotetext{
${ }^{12}$ We assume that the firm can only order a worker to work on task $E$, because it is inherently much easier to force someone to work on a routine and standardized task. In contrast, since no one knows ex ante what kind of resources is indispensable to come up with and carry out new procedures, the firm must grant the workers full access to all the critical resources, which necessarily includes those that are indispensable to carry out the routine task. There is hence no realistic enforcement mechanism to prohibit a worker to work on task E.
} 
Information: Once the firm determines the extent of job discretion, it only plays a passive role thereafter; its only remaining job is to choose which worker to promote, after observing the outputs $\left(y_{1}, \ldots, y_{n}\right) \cdot{ }^{13}$ Let $x_{i} \in\{0,1\}$ denote the promotion outcome for worker $i$, where $x_{i}=1$ if he is promoted and $x_{i}=0$ otherwise, with the restriction that $\sum_{i=1}^{n} x_{i}=1$. We assume that neither the output nor the task choice is verifiable, so that no contingent contract (wage and promotion rules) can be enforced.

Payoffs: Each worker receives a wage and, if he is promoted, a promotion bonus. In the absence of complete contracts, each worker's wage is determined though ex post Nash bargaining with some exogenous share $\lambda$. The payoff for worker $i$ is then given by

$$
u_{i}=\lambda y_{i}+B x_{i}
$$

where $B \geq 0$ measures the relative salience of the promotion bonus which includes all the expected benefits accruing from a promotion, such as pay raises, various fringe benefits, high prestige, and so on. For now, we assume that $B$ is determined largely by outside market conditions and is hence given exogenously. Let $b:=\frac{B}{\lambda}$ for normalization.

The firm's payoff, on the other hand, depends positively on each worker's output and the ability of the promoted worker. The fact that the firm cares about the ability of the promoted worker directly gives rise to the assignment role of promotion. The payoff for the firm, denoted by $u_{0}$, is given by

$$
u_{0}=(1-\lambda) \frac{\sum_{i=1}^{n} y_{i}}{n}+\Gamma_{n} \eta_{s}
$$

where the promoted worker is denoted by $i=s$. The parameter $\Gamma_{n}>0$ measures the importance of managerial skills in the firm's production process and hence the salience of the assignment role of promotion relative to the incentive role. Note that $n \Gamma_{n}$ measures the total value of assignment to the firm, where we assume that $n \Gamma_{n}$ is weakly increasing in $n$ with some finite upperbound $\lim _{n \rightarrow \infty} n \Gamma_{n}=\bar{\Gamma}<\infty$. As above, let $\gamma_{n}:=\frac{\Gamma_{n}}{1-\lambda}$.

Timing: The sequence of events is summarized as follows:

1. Nature draws the ability types $\left(\eta_{1}, \eta_{2}, \ldots, \eta_{n}\right)$.

2. The firm chooses whether to delegate or not.

\footnotetext{
${ }^{13}$ In this context, it does not matter whether the task choice is observable or not. Because of the way we specify the model, the output level is effectively a sufficient statistic, and the observability of the task choice is totally irrelevant.
} 
3. If the firm chooses to delegate, each worker chooses which task to perform.

4. Upon observing the realized outputs $\left(y_{1}, y_{2}, \ldots, y_{n}\right)$, the firm chooses a worker to promote.

5. The payoffs are realized.

Remarks on the underlying environment: Before we proceed to analyzing the model, we would like to make some remarks about the current setup in order to clarify the scope of the analysis. Two aspects of the model are especially critical and virtually define the nature of the underlying situation.

1. The contracting environment we consider is extremely incomplete in that nothing is directly tied to the observable output, possibly due to the unverifiability of performance measures. While this aspect gives rise to the incentive role of promotion, where workers are motivated though the prospect of promotion, it also implies that the firm cannot commit to any contingent promotion rule either. The combination of these two restrictions put the firm in a difficult situation where it must use promotions not only to allocate but also to motivate its workers, and moreover must do so without any commitment devices, i.e., contracts, at its disposal.

2. The second aspect, which appears more innocuous but is nonetheless equally important, is the fact that the production process inherently involves some uncertainty: although there is an established routine (task $E$ ), it is not clear whether that would provide the most efficient way to produce output in this particular environment. The spirit of this aspect is exemplified in the task choice problem where each worker chooses which task to implement.

We argue that the problem of this kind abounds in typical firm organizations. First, in many cases, it is either practically impossible or prohibitively costly to measure all dimensions of performances objectively. In any event, it is in practice very rare to find a firm which specifies fully contingent promotion rules in an unambiguous way. Moreover, there is little doubt that workers get both tangible and intangible rewards from promotions: at the very least, wages are tied strongly with ranks in most firms. ${ }^{14}$

\footnotetext{
${ }^{14}$ There is a large literature which examines the so-called Baker-Jensen-Murphy puzzle (1988), i.e., why
} 
The second aspect is also common and relevant, particularly in newly emerging industries where established procedures are not necessarily the most efficient. In such an environment, the firm must rely on its workers' creativity in search of new ideas and methods. If the firm confers some discretion over task choice decisions, some workers may attempt to exploit the existing knowledge more (task $E$ ) while others may attempt to explore and experiment with what could prove to be truly innovative ideas (task $D$ ). In this uncertain environment, the conflict between the two roles of promotion is more likely to surface because a worker's immediate output alone may no longer be an accurate indicator of how productive he will be in the future.

\section{Analysis}

\subsection{The efficient task choice rules}

Before we analyze the model, we first characterize the efficient task choice rules which the firm would implement if it could enforce a complete contract contingent on the output $y_{i}$ (though not directly on the task choice). To this end, note first that since the surplus gained from assigning a worker to task $D$ is increasing in $\eta_{i}$, any efficient rule is characterized by a threshold $\tilde{\eta}$ such that a worker is assigned to task $D$ if and only if $\eta_{i} \geq \tilde{\eta}$. Then, the firm can implement any efficient task choice rule by appropriately designing an incentive scheme. To see this more clearly, suppose that each worker's reservation payoff is zero, and the firm offers a (take-it-or-leave-it) contract $w\left(y_{i}\right)$. Then, for any $\tilde{\eta} \in[0,1]$, the following contract implements the desired task choice rule at almost no cost:

$$
w\left(y_{i}\right)= \begin{cases}\varepsilon & \text { if } y_{i} \geq \tilde{\eta} \\ 0 & \text { if } y_{i}=\theta, \\ -D & \text { if } y_{i}<\tilde{\eta} \text { and } y_{i} \neq \theta\end{cases}
$$

where $\varepsilon>0$ is some infinitesimally small number and $D>0$. Given this contract, it is indeed optimal for a worker to choose task $D$ if and only if $\eta_{i} \geq \tilde{\eta}$.

The efficient task choice rule is thoroughly characterized by the threshold $\tilde{\eta}$. Here, we consider two different efficiency criteria. First, the problem would be much simpler in the absence of information asymmetry because the firm only needs to concentrate on incentive

firms ever use promotions to reward workers when they can also use monetary rewards to induce worker motivation. See Malcomson (1984), Prendergast (1993), Fairburn and Malcomson (2001) for various accounts for this puzzle. 
provision in this case. The first-best task choice rule - the task choice rule which the firm would implement when each worker's ability type is publicly observable - is such that a worker chooses task $D$ if and only if $\eta_{i} \geq \theta$. Note that the first-best task choice rule is the one which maximizes the expected total output.

The notion of first-best efficiency is not necessarily appropriate, however, when each worker's ability type is his private information. In the presence of information asymmetry, there is also a gain from experimentation, i.e., from assigning a worker to task $D$ in order to induce his private information, and the efficiency criterion may need to take this gain into account. To this end, let $S(\tilde{\eta})$ denote the total surplus (per worker) when all workers with $\eta_{i} \geq \tilde{\eta}(\eta<\tilde{\eta})$ are assigned to task $D(E)$. We then obtain

$$
S(\tilde{\eta})=\theta F(\tilde{\eta})+\int_{\tilde{\eta}}^{1} \eta d F+\Gamma_{n}\left(\mu\left(\tilde{\eta}_{n}\right) F\left(\tilde{\eta}_{n}\right)^{n}+\int_{\tilde{\eta}_{n}}^{1} \eta d F_{\eta_{(n)}}\right),
$$

where $F_{\eta_{(k)}}$ is the distribution of the $k$-th order statistic $\eta_{(k)}$ with its corresponding density $f_{\eta_{(k)}}$. Define $\eta^{\mathrm{SB}}$ as the second-best task choice threshold, which is given by

$$
\eta^{\mathrm{SB}}=\operatorname{argmax}_{\tilde{\eta} \in[0,1]} S(\tilde{\eta})
$$

The first-order condition implies that the second-best threshold must solve

$$
\left(\theta-\eta^{\mathrm{SB}}\right) f\left(\eta^{\mathrm{SB}}\right)+\Gamma_{n}\left(\eta^{\mathrm{SB}} f\left(\eta^{\mathrm{SB}}\right) F\left(\eta^{\mathrm{SB}}\right)^{n-1}+f_{\eta_{(n-1)}}\left(\eta^{\mathrm{SB}}\right) \int_{0}^{\eta^{\mathrm{SB}}} \eta d F-\eta^{\mathrm{SB}} f_{\eta_{(n)}}\left(\eta^{\mathrm{SB}}\right)\right)=0 .
$$

Since $f_{\eta_{(n)}}=n F^{n-1} f$, we have

$$
\theta-\eta^{\mathrm{SB}}+\Gamma_{n}\left(\eta^{\mathrm{SB}} F\left(\eta^{\mathrm{SB}}\right)^{n-1}+(n-1) F\left(\eta^{\mathrm{SB}}\right)^{n-2} \int_{0}^{\eta^{\mathrm{SB}}} \eta d F-n \eta^{\mathrm{SB}} F\left(\eta^{\mathrm{SB}}\right)^{n-1}\right)=0
$$

which is further reduced to

$$
\theta-\eta^{\mathrm{SB}}=(n-1) \Gamma_{n} F\left(\eta^{\mathrm{SB}}\right)^{n-1}\left(\eta^{\mathrm{SB}}-\mu\left(\eta^{\mathrm{SB}}\right)\right) .
$$

Because of the value of experimentation, the second-best threshold $\eta^{\mathrm{SB}}$ is strictly lower than the first-best threshold $\theta$. Note, however, that the second-best threshold coincides with the first-best when $n=1$ and also converge to the first-best as $n \rightarrow \infty$.

\subsection{Time inconsistency}

As can be seen, the problem is quite straightforward when the firm can enforce complete contracts contingent on each worker's output. In many cases, though, it is not feasible to 
do so, e.g., because performance measures are often not verifiable, and the firm must instead motivate its workers through the prospect of promotion. This restriction poses a serious difficulty for the firm. To see this, recall that a worker's (normalized) payoff is given by $y_{i}+b x_{i}$. Note that the first term represents a common interest, so that any distortion in this context must arise from the second term. Given this, it appears that the conflict of interest would be alleviated by committing to a promotion rule under which the firm simply promotes the worker who have produced the highest output. Because the workers are only concerned about maximizing their own outputs under this rule and use their private information to that end, the firm can effectively implement the first-best task choice rule. ${ }^{15}$

The problem is that given that contingent wage contracts are not feasible, it is also highly unlikely that the firm can enforce such a contingent promotion rule. In the absence of credible commitment, it is generally impossible to implement the first-best task choice rule since the firm has no incentive to enforce this promotion rule ex post: once the task choices have been made, the firm is always tempted to choose the worker with the highest expected ability, inferred from the observed output level, rather than the one with the highest output. This is a typical time-inconsistency problem which occurs when one side of the parties must take an irreversible action, and the other side subsequently has an opportunity to take advantage of it. The time-inconsistent nature of the two roles of promotion obviously influences the workers' incentives, as we discuss next.

\subsection{The task choice problem}

We first consider the problem faced by each worker, given that the firm chooses to decentralize. For the analysis, we restrict our attention to symmetric equilibria of the following form: there exists a common cutoff $\bar{\eta}_{n}$ for all $i$ such that worker $i$ chooses task $D$ if and only if $\eta_{i} \geq \bar{\eta}_{n}$. Let $\sigma_{i}$ denote the firm's belief concerning worker $i$ 's ability type. Given the cutoff strategy, the firm's belief is obtained as

$$
\sigma_{i}=\sigma\left(y_{i}\right)= \begin{cases}y_{i} & \text { if } y_{i} \neq \theta \\ \mu\left(\bar{\eta}_{n}\right) & \text { if } y_{i}=\theta\end{cases}
$$

The ex post optimal promotion rule is to choose the agent with the highest $\sigma_{i}$ rather than the one with the highest $y_{i} \cdot{ }^{16}$

\footnotetext{
${ }^{15}$ Of course, if it is feasible to enforce a promotion rule contingent on the output, the firm can also design a more complicated promotion rule and implement other task choice rules as well.

${ }^{16}$ When there is a tie, we assume that the winner is determined by a coin flip.
} 
Given the ex post optimal promotion rule and the cutoff $\bar{\eta}_{n}$, each worker computes the promotion probability contingent on his task choice. Let $q_{k}(\eta)$ denote the promotion probability when a worker with ability $\eta$ chooses task $k, k=E, D$. If a worker chooses task $E$, he will be promoted only when all of the other workers choose task $E$ as well (and win the tie-break). We thus have

$$
q_{E}\left(\eta_{i}\right)=\frac{F\left(\bar{\eta}_{n}\right)^{n-1}}{n}
$$

which is totally independent of the ability type $\eta_{i}$. If a worker chooses task $D$, on the other hand, the promotion probability depends on the ability type and is given by

$$
q_{D}\left(\eta_{i}\right)= \begin{cases}F\left(\eta_{i}\right)^{n-1} & \text { for } \eta_{i} \in\left[\bar{\eta}_{n}, 1\right], \\ F\left(\bar{\eta}_{n}\right)^{n-1} & \text { for } \eta_{i} \in\left[\mu\left(\bar{\eta}_{n}\right), \bar{\eta}_{n}\right), \\ 0 & \text { for } \eta_{i} \in\left[0, \mu\left(\bar{\eta}_{n}\right)\right) .\end{cases}
$$

It follows from these that worker $i$ chooses task $D$ over task $E$ if

$$
\eta_{i}+b q_{D}\left(\eta_{i}\right) \geq \theta+b q_{E}\left(\eta_{i}\right)
$$

which must hold with equality at the cutoff ability type in equilibrium:

$$
\bar{\eta}_{n}+b q_{D}\left(\bar{\eta}_{n}\right)=\theta+b q_{E}\left(\bar{\eta}_{n}\right)
$$

Rearranging this yields

$$
\theta-\frac{n-1}{n} b F\left(\bar{\eta}_{n}\right)^{n-1}=\bar{\eta}_{n} .
$$

Proposition 1 For any given $\theta, n$ and $b$, there exists a unique cutoff ability level $\bar{\eta}_{n}$ which is strictly lower than $\theta$ for $n \geq 2$ and $b>0$. Moreover, $\eta^{\mathrm{SB}}>\bar{\eta}_{n}$ if

$$
b>n \Gamma_{n}(\theta-\mu(\theta)) .
$$

Proof: Let

$$
H_{n}(\eta ; b)=\theta-\frac{n-1}{n} b F(\eta)^{n-1}
$$

or simply $H_{n}(\eta)$, so that the equilibrium cutoff level is given by a fixed point $\bar{\eta}=H_{n}(\bar{\eta})$. There exists a unique cutoff because $H_{n}^{\prime}<0, \lim _{\eta \rightarrow 0}\left[H_{n}(\eta)-\eta\right]=\theta>0$, and $\lim _{\eta \rightarrow \theta}\left[H_{n}(\eta)-\eta\right]=$ $-\frac{n-1}{n} b F(\theta)^{n-1}<0$ for any $n$ and $b$. It also follows from this that $\bar{\eta}_{n}<\theta$ for $n \geq 2$ and $b>0$. 
Second, a sufficient condition for $\eta^{\mathrm{SB}}>\bar{\eta}_{n}$ is

$$
\frac{n-1}{n} b F(\eta)^{n-1}>(n-1) \Gamma F(\eta)^{n-1}(\eta-\mu(\eta)) \Leftrightarrow b>n \Gamma_{n}(\eta-\mu(\eta))
$$

for all $\eta \in[0, \theta]$. This is the case if and only if

$$
b>n \Gamma_{n}(\theta-\mu(\theta)) .
$$

The fact that $\theta>\bar{\eta}_{n}$ implies that task choice in this context is generally inefficient compared to the first-best level in that too many workers opt for task $D$ to signal their abilities. Moreover, when $b$ is sufficiently large, the threshold goes below the second-best level. Figure 1 illustrate a typical equilibrium and the associated output loss. The root of the problem lies in the firm's inability to commit to the ex ante optimal promotion rule which evaluates workers solely on how much they have produced and hence contributed to the firm in the past. Given that the firm cannot make credible commitments, however, the assignment role of promotion always dominates the incentive role ex post, which provides workers with an excessively strong incentive to signal their abilities.

[Figure 1 here]

The cutoff level depends largely on two factors - the relative salience of the promotion bonus $b$ and the number of workers $n$. We first consider the impact of changes in $b$ which is relatively straightforward. An increase in $b$ shifts each worker's attention away from output maximization to ability signaling, which exacerbates the inefficiency in task choice. In particular, as $b$ tends to infinity, the signaling motive becomes so dominant that the cutoff level goes down to the lowerbound and almost everyone chooses task $D$. One can also see that the first-best efficiency is achieved only when $b=0$, i.e., there is no direct return to being promoted.

Proposition 2 The cutoff level is monotonically decreasing in b. Moreover, $\lim _{b \rightarrow 0} \bar{\eta}_{n}=\theta$ and $\lim _{b \rightarrow \infty} \bar{\eta}_{n}=0$ for any $n$.

Proof: It is evident that an increase in $b$ lowers the cutoff since $\frac{\partial H_{n}}{\partial b}<0$ for any $\eta$. Note also that $H_{n}(\eta ; 0)=\theta$ which implies that $\bar{\eta}_{n}=\theta$ when $b=0$. Finally, the cutoff level must 
satisfy

$$
\frac{\theta}{b}-\frac{n-1}{n} F\left(\bar{\eta}_{n}\right)^{n-1}=\frac{\bar{\eta}_{n}}{b}
$$

As $b \rightarrow \infty$, this becomes

$$
-\frac{n-1}{n} F\left(\bar{\eta}_{n}\right)^{n-1}=0
$$

which implies that $\lim _{b \rightarrow \infty} \bar{\eta}_{n}=0$.

We now consider the effect of a change in $n$. Since only one worker will be promoted in the end, the number of competing workers $n$ captures the intensity of the promotion competition in the firm. An increase in $n$ gives rise to two distinct effects. The first effect is that it decreases $q_{E}$, i.e., the probability that a worker who chooses task $E$ is promoted, which in turn reduces the incentive to choose task $E$. There is also a countervailing effect, however, as an increase in $n$ decreases the probability that all the other workers choose task $E$, which works to reduce the incentive to choose task $D$. The overall impact is determined by which effect eventually dominates.

Proposition 3 There exists $\bar{n}$ such that $\bar{\eta}$ is decreasing in $n$ for $\bar{n} \geq n$ and increasing for $n>\bar{n}+1$. Moreover, $\bar{\eta}_{1}=\lim _{n \rightarrow \infty} \bar{\eta}_{n}=\theta$.

Proof: The second part of the proposition, i.e., $\bar{\eta}_{1}=\lim _{n \rightarrow \infty} \bar{\eta}_{n}=\theta$, is obtained straightforwardly from (1). For the first part, we treat $n$ as if it is continuous. The cutoff level $\bar{\eta}_{n}$ increases with $n$ if

$$
\left.\frac{\partial H}{\partial n}\right|_{\eta=\bar{\eta}_{n}}=-\frac{1}{n^{2}} b F\left(\bar{\eta}_{n}\right)^{n-1}-\frac{n-1}{n} b F\left(\bar{\eta}_{n}\right)^{n-1} \ln F\left(\bar{\eta}_{n}\right)>0,
$$

which is simplified to

$$
-\ln F\left(\bar{\eta}_{n}\right)>\frac{1}{n(n-1)}
$$

This means that $\bar{\eta}_{n}$ is decreasing in $n$ at $n=1$ and increasing when $n$ is sufficiently large. Then, there must exist at least one $\tilde{n}$ such that

$$
-\ln F\left(\bar{\eta}_{\tilde{n}}\right)=\frac{1}{\tilde{n}(\tilde{n}-1)}
$$


Let $\tilde{n}_{0}$ is the smallest one which satisfies (2). We can then show that it is the only one which can satisfy (2). To see this, suppose that there exists $\tilde{n}_{1}>\tilde{n}_{0}$ which satisfies (2). Notice the slope of the right-hand side of (2) is always negative, meaning that the slope of the left-hand

side must also be negative at $n=\tilde{n}_{1}$. This is a contradiction because $\left.\frac{\partial \bar{\eta}_{n}}{\partial n}\right|_{n=\tilde{n}_{1}}=0$ and the slope must be zero at this point by definition. Given the uniqueness of $\tilde{n}, \bar{n}$ is defined as the largest integer which satisfies $\bar{n}+1>\tilde{n}>\bar{n}$.

The relationship between $\bar{\eta}_{n}$ and $n$ is $\mathrm{U}$-shaped, where more intense competition lowers the efficiency up to some point and then improves it thereafter. This suggests that the inefficiency in task choice is most serious when $n$ is in some intermediate range - the case that can presumably be applied to many organizations. In contrast, task choice is fully efficient at both ends. First, when $n=1$, the worker is guaranteed to be promoted, and there is hence no internal competition whatsoever. The worker's incentive coincides exactly with the firm's regardless of $b$ because he has no need to "show off" his talent. On the other hand, when $n$ is sufficiently large, the promotion competition now becomes so severe that the prospect of promotion is negligibly small for almost all workers. This again shifts each worker's attention more towards output maximization and hence makes his task choice more efficient. In either case, when $n$ is too small or too large, the task choice problem is less strategic in that each agent's behavior is less dependent on what others do.

Note also that both $\eta^{\mathrm{SB}}$ and $\bar{\eta}_{n}$ converge to the first-best level $\theta$ as $n \rightarrow \infty$. One can then easily show that $\eta^{\mathrm{SB}}>\bar{\eta}$ for all $n$ if $b>\bar{\Gamma}(\theta-\mu(\theta))$. If $\bar{\Gamma}(\theta-\mu(\theta))>b$, on the other hand, the speed of convergence is faster for $\bar{\eta}_{n}$, so that $\bar{\eta}_{n}>\eta^{\mathrm{SB}}$ for $n$ sufficiently large.

\subsection{Promotion and job discretion}

When the firm cannot commit to the ex ante optimal promotion rule, each worker's career concerns distort his task choice if he is given full discretion over what to do. Given the firm's inability to commit, one way to mitigate this problem is to limit job discretion altogether and unilaterally assign tasks to the workers. The cost of centralization is then evident. One obvious problem which stems from this is that the task allocation becomes necessarily inefficient in that some competent workers are forced to work on routine tasks. Moreover, in the context where the assignment role of promotion is also important, centralization entails an additional efficiency loss because by forcing every worker to work on the same set of routine 
tasks, it becomes harder for the firm to differentiate the workers and identify the right one to promote. Despite these apparent problems, however, centralization may still prove to be optimal for the firm when the distortion under decentralization is severe enough.

To see when it is optimal to limit job discretion, consider first the case of decentralization where each worker is conferred full authority over what to do. Under decentralization, the workers are separated and sorted according to their own abilities. The expected payoff under decentralization is computed as

$$
\theta F\left(\bar{\eta}_{n}\right)+\int_{\bar{\eta}_{n}}^{1} \eta d F+\gamma_{n}\left(\mu\left(\bar{\eta}_{n}\right) F\left(\bar{\eta}_{n}\right)^{n}+\int_{\bar{\eta}_{n}}^{1} \eta d F_{\eta_{(n)}}\right) .
$$

If the workers are restricted to work on task $E$, on the other hand, the expected output is $\theta$ for any realization of $\left(\eta_{1}, \eta_{2}, \ldots, \eta_{n}\right)$. Since the workers are pooled and hence identical from the firm's viewpoint, it must randomly pick one of them with the expected ability of $\mu$. The expected payoff is thus $\theta+\gamma_{n} \mu$.

Given the preceding argument, it is optimal to limit job discretion via centralization if

$$
\theta+\gamma_{n} \mu>\theta F\left(\bar{\eta}_{n}\right)+\int_{\bar{\eta}_{n}}^{1} \eta d F+\gamma_{n}\left(F\left(\bar{\eta}_{n}\right)^{n} \mu\left(\bar{\eta}_{n}\right)+\int_{\bar{\eta}_{n}}^{1} \eta d F_{\eta_{(n)}}\right),
$$

which can further be reduced to

$$
\int_{\bar{\eta}_{n}}^{1}(\theta-\eta) d F>\gamma_{n}\left(\int_{0}^{\bar{\eta}_{n}}\left(\mu\left(\bar{\eta}_{n}\right)-\mu\right) d F_{\eta_{(n)}}+\int_{\bar{\eta}_{n}}^{1}(\eta-\mu) d F_{\eta_{(n)}}\right) .
$$

One can easily see that the right-hand side of (3) is always strictly positive for any $\gamma>0$. Centralization is then optimal if the right-hand side, which measures the loss of output due to the inefficiency in task choice, is positive and sufficiently large.

The condition (3), along with (1), allows us to identify factors which could influence the optimal degree of decentralization. Among those factors, we here focus on three of them, which offer some interesting implications to be discussed later. The first is the firm's productivity relative to the existing stock of knowledge $\theta$ : in the current context, a highproductivity firm can be regarded as the one in which the distribution is skewed more towards the high end and $F(\theta)$ is relatively small. To see how the level of human capital affects the cost of decentralization, consider a high-productivity firm with $F(\theta)=\varepsilon$. One can then show that as $\varepsilon \rightarrow 0$, the cutoff ability level converges to the first-best level, meaning that decentralization imposes no cost to the high-productivity firm (note that the second-best 
threshold $\eta^{\mathrm{SB}}$ also converges to the first-best level, so that the allocation is fully efficient). This is summarized as follows.

Proposition 4 Decentralization is optimal if $F(\theta)$ is sufficiently small.

Proof: As $F(\theta) \rightarrow 0, \bar{\eta}_{n} \rightarrow \theta$, and (3) becomes

$$
\int_{\theta}^{1}(\theta-\eta) d F>\gamma_{n}\left(\int_{0}^{\theta}(\mu(\theta)-\mu) d F_{\eta_{(n)}}+\int_{\theta}^{1}(\eta-\mu) d F_{\eta_{(n)}}\right)=\gamma_{n} \int_{\theta}^{1}(\eta-\mu) d F_{\eta_{(n)}} .
$$

This never holds as $\int_{\theta}^{1}(\theta-\eta) d F<0$.

The second key factor is the number of competing workers $n$ which obviously bears critical impacts on each worker's signaling motives. As can be seen from proposition 2, task choice is fully efficient when $n=1$ and $n \rightarrow \infty$, which implies that decentralization entails less cost at both ends. We can then immediately obtain the following result.

Proposition 5 Decentralization is optimal when $n$ is either sufficiently small or sufficiently large.

Proof: For $n=1,(3)$ becomes

$$
\int_{\theta}^{1}(\theta-\eta) d F>\gamma_{1}\left(\int_{0}^{\theta}(\mu(\theta)-\mu) d F+\int_{\theta}^{1}(\eta-\mu) d F\right)=0
$$

which never holds since $\int_{\theta}^{1}(\theta-\eta) d F<0$. Similarly, as $n \rightarrow \infty$,

$$
\int_{\theta}^{1}(\theta-\eta) d F>\lim _{n \rightarrow \infty} \gamma_{n}(1-\mu)=0
$$

which never holds either.

The final factor is the value of managerial skills as captured by $\gamma_{n}$. As is clear from (3), an increase in $\gamma_{n}$ makes the assignment role of promotion a predominant concern for the firm. Decentralization is indispensable to induce each worker's private information, although it necessarily means a loss of control by the firm. When $\gamma_{n}$ is large enough, the assignment role of promotion dominates the incentive role, and it becomes optimal to confer job discretion to the workers. 
Proposition 6 There exists some $\bar{\gamma}_{n}>0, n \geq 2$, such that centralization is optimal for all $\bar{\gamma}_{n} \geq \gamma_{n}$ if $\theta$ is sufficiently close to one.

Proof: We simply need to show that the left-hand side of $(3)$ is positive, i.e., $\int_{\bar{\eta}_{n}}^{1}(\theta-\eta) d F>0$. We have already seen that $\theta>\bar{\eta}_{n}$ for $n \geq 2$. Then, as $\theta \rightarrow 1$, this condition becomes $\int_{\bar{\eta}_{n}}^{1}(1-\eta) d F>0$, which holds if $1>\bar{\eta}_{n}$.

\section{Discussion}

\subsection{Determining factors of decentralization}

The current model provides a framework to clarify the determinants of decentralization, which is of particular importance because decentralization is regarded as one of the key modern management practices which have critical impacts on the firm's overall productivity. Three factors - the firm's relative productivity (proposition 4), the number of competing workers (proposition 5), and the importance of managerial skills (proposition 6) - are shown to be crucial. In this subsection, we derive further implications of these results and interpret them in light of recent empirical findings.

Human capital: A strong association seems to exist between human capital and decentralization. Caroli and Van Reenen (2001) and Breshnahan et al. (2002) find evidence for the existence of complementarities between organizational changes, as characterized by decentralization of authority, and skills. Bloom et al. (2010, 2011) also find consistently that firms with more skilled workers are more decentralized. This is consistent with one of our main predictions that decentralization imposes no cost to high-productivity firms which are more likely to diversify decision rights and confer a larger degree of autonomy among its workers.

Market competition: A broad view in economics is that market competition enhances efficiency since it weeds out any suboptimal behavior. Given that modern management practices can be regarded as a form of innovation, there is a pervasive belief that market competition encourages firms to adopt more modern, and more efficient, management practices including the delegation of authority lower down the firm hierarchy. This view is roughly confirmed by Bloom et al. (2010) who find that competition seems to foster decentralization. Rajun and Wulf (2006) raise market competition as a potential factor behind the recent movement towards delayering of corporate hierarchies. Similarly, Guadalupe and Wulf (2010) find that 
greater competition causes firms to adopt flatter corporate hierarchies, using the Canada-US Free Trade Agreement (FTA) as a quasi-natural experiment. ${ }^{17}$ As more indirect evidence, Acemoglu et al. (2007) also emphasize that firms tend to decentralize when the value of local information, compared to that of public information, is high. Then, to the extent that market competition raises the value of local information, greater competition induces more firms to decentralize.

It is intuitively clear that once we accept that decentralization is a form of innovation, market competition exerts a direct impact on the extent of decentralization simply because firms with less efficient management practices are less likely to survive in competitive environments. Aside from this direct effect, market competition could also induce firms to decentralize if it somehow raises the value of managerial skills. ${ }^{18}$ Besides its intuitive appeal, there is some indication that this premise is indeed a valid one to assume. For instance, market competition is positively correlated not only with productivity (Nickell, 1996; Syverson, 2004), but also with the quality of management practices (Bloom and Van Reenen, 2010), which suggests that greater market competition could intensify the need for high-quality management. Moreover, market competition may also function as a disciplining device to mitigate managerial slack. Several theoretical works establish that market competition is more likely to result in higher effort provision by managers (Hart, 1983; Schmidt, 1997). The nature of competition also shapes the incentive structure within the firm: Cunat and Guadalupe (2005, 2009) find that a higher degree of market competition increases the performance pay sensitivity of compensation schemes, which could result in higher effort provision. Given that effort and managerial skills are complementary, these findings suggest that market competition generally raises the value of managerial skills, which in turn raises the importance of assignment and hence favors decentralization.

Distance to the technology frontier: Using data on French and British firms, Acemoglu et al. (2007) find that firms closer to the technology frontier are more likely to be decentralized. ${ }^{19}$ The distance to the technology frontier could have a profound impact on the extent

\footnotetext{
${ }^{17}$ Of course, there is no inherent connection between delayering and decentralization, as the effect of delayering can go in either direction. There seems to be some indication, however, that delayering is positively associated with decentralization. We explore more on this point in section 4.1.

${ }^{18}$ It should be noted, though, that the correlation could in principle go in either direction. Since good management can be regarded as a form of technology, the argument runs parallels to that concerning the relationship between competition and innovation. The theoretical relationship between them is not clear, as there are both positive (the Arrowian effect) and negative effects (the Schumpeterian effect).

${ }^{19}$ Their argument emphasizes the role of local information as a determinant for the extent of decentralization.
} 
of decentralization in the current setup as well.

There are two alternative ways to make this connection, each of which is closely related to the argument made above. First, firms closer to the technology frontier can be interpreted as the ones that are technologically advanced relative to the existing stock of knowledge. Since each worker's productivity is high relative to $\theta$, one can argue that $F(\theta)$ is relatively small for those firms. The same argument as in the case of human capital then applies here: the cost of decentralization is smaller when $F$ is skewed upwards, and decentralization emerges as the optimal choice when $F(\theta)$ is sufficiently small.

There is also a more indirect channel which works through its effect on the value of managerial skills. As Acemoglu et al. (2006) argue, managerial skills matter more in environments where innovation, rather than adaptation, is the main concern. ${ }^{20}$ Applying this logic, since a firm needs to rely more on innovation where there is little room to learn from public information, the value of managerial skills is expected to rise as the firm gets closer to the technology frontier. The distance to the technology frontier then plays an identical role to market competition: the value of managerial skills $\gamma_{n}$ tend to be larger for firms closer to the technology frontier which in turn face stronger incentives to decentralize.

Firm size and delayering: The number of competing workers within an organization is another important determinant of decentralization. It follows from proposition 5 that the cost of decentralization decreases as the number of competing workers $n$ gets larger (after some point), so that decentralization is more likely to prevail when $n$ is sufficiently large. There are two implications that can be derived form this observation.

First, in the long run, the number of competing workers is ultimately determined by the size of the firm. The model then predicts that the cost of decentralization diminishes as the firm size gets larger. When the firm size is sufficiently large, the probability that a low-productivity worker is mistakenly promoted becomes very slim, because there is almost surely someone who is more productive, leaving little room for manipulating information through task choices. In this context, therefore, the cost of decentralization is less in larger

They argue that firms need to decentralize more when the value of local information is sufficiently high compared to that of public information. This leads them to hypothesize that firms closer to the technology frontier are more likely to be decentralized, because they are less likely to learn from public information.

${ }^{20}$ Market competition may also play a role through this channel, if the value of innovation is higher in more competitive environments. For instance, Nickell (1996) and Blundell (1999) find a positive association between market competition and innovation. Aghion et al. (2005) find that the relationship is non-monotonic and exhibits an inverted-U shape although the correlation seems to be positive for a substantial range of market competition. 
firms since severer competition works to discipline workers and makes their objectives more aligned squarely with the firm's. This implication is largely consistent with recent evidence by Bloom et al. (2010) and Bloom and Van Reenen (2010) that larger firms are more decentralized.

In the short run, promotion competition may involve only workers in related divisions, and hence the number of competing workers depends crucially on how the firm organization is layered into different business units. In general, there seems to be a movement towards flatter and simpler corporate hierarchies, partly triggered by the recent advent of information technology, which implies that there are less "intermediate positions" available, yielding an effect analogous to an increase in $n .^{21}$ The same logic then applies here: internal competition among workers aligns their incentives more closely with the firm's, and decentralization hence imposes less cost to the firm when $n$ is larger. ${ }^{22}$ This prediction is roughly in line with evidence by Rajan and Wulf (2006) who find that delayering is often associated with pay increases of divisional managers, which they take as an indication of decentralization. ${ }^{23}$

Distorted promotion incentives: The driving force of the model is built on the premise that the firm uses promotions to allocate workers where they belong and has an incentive to identify and select the most deserving worker ex post. This logic is hence less applicable if the firm's incentives are distorted for some reasons, and it is not particularly concerned about the assignment role of promotion, e.g., in a case where there is a predetermined winner, or the "heir apparent," who is sure to be promoted. To see this, consider an asymmetric tournament in which there is a worker who is promoted with probability $r$ regardless of his performances; with the remaining probability, the firm promotes the worker with the highest ability. Letting $\eta_{p}$ denote the ability type of the preferred worker and normalizing, the firm's

\footnotetext{
${ }^{21}$ For instance, Rajan and Wulf (2006) document that the span of control is increasing (the number of managers reporting to the CEO has increased steadily over time, from 1986 to 1998) and the number of layers in firm hierarchy is decreasing (the number of positions between the CEO and the division heads has decreased over the same span).

${ }^{22}$ It should be noted, though, that there is a caveat for these interpretations. In deriving these implications, we only consider the effect of an increase $n$ while taking $b$ fixed. This may not necessarily be a fair comparison since the gains that accrue from a promotion could also increase with $n$. Our logic implies, however, that the effect of an increase in $n$ is exponential and typically dominates that of a proportional increase in $b$ (see proposition 7 in Appendix for more detail). In light of this, we claim that decentralization is more likely to prevail in larger organizations or business units.

${ }^{23} \mathrm{It}$ is important to note that it is not a priori clear whether delayering itself means more decentralization or less: on one hand, middle managers can directly communicate with the CEO, which might imply more autonomy for them; on the other hand, the large span of control could imply more direct control and intense monitoring by the CEO.
} 
payoff function becomes

$$
u_{0}=\frac{\sum_{i=1}^{n} y_{i}}{n}+\gamma_{n}\left(r \eta_{p}+(1-r) \eta_{s}\right)
$$

Since $\eta_{p}$ is exogenous to the model and can be ignored, the presence of the preferred worker yields an impact equivalent to a decrease in $\gamma_{n}$, which in turn favors centralization. ${ }^{24}$

Promotion incentives are distorted whenever a person in charge derives private benefits from promoting a particular worker regardless of his qualifications, as it diminishes the value of experimentation through decentralization. One factor that bears a critical impact on this is the ownership structure of a firm, where diversified ownership diminishes the role of private benefits. One evidence in line of this argument is the finding that family firms, especially those in which the $\mathrm{CEO}$ is chosen by primogeniture, are on average badly managed and substantially less decentralized (Bloom and Van Reenen, 2007, 2010).

Social capital: Recently, economists have become increasingly aware of the importance of culture as a potential determinant of economic outcomes (see Guiso, Sapienza, and Zingales, 2006, for a survey). Among those cultural factors, one critical factor seems to be the level of social capital, often proxied by the level of trust. There is now an abundance of evidence that trust fosters faster growth (La Porta et al., 1997). Although not much is know about the underlying mechanism which links trust with economic performances, one convincing evidence for why trust matters for economic performances is provided by Bloom, Sadun and Van Reenen (2011) who find a strong association between trust and decentralization: firms in a high-trust region are more decentralized. A firm with a high level of trust is able to decentralize and hence effectively utilize local information available only to its workers, which in turn spurs its productivity.

The current model provides one potential route through which intangible social capital such as trust could influence the firm's productivity though its choice on the extent of decentralization. As we have already argued, the firm can implement the first-best task allocation by committing to a rule which promotes the worker with the highest output. Under this promotion rule, each agent uses his private information only to maximize the output, which

\footnotetext{
${ }^{24}$ The presence of the preferred worker may also affect the other workers' incentives as it severely limits the prospect of promotion for them. This could yield an effect equivalent to a decrease in $B$ which favors decentralization. We argue, however, that the distorted incentive structure is more likely to result in centralization because workers' career concerns are not necessarily confined within the boundary of the firm organization: if a worker can signal his productivity to outside firms to some extent, the distorted incentive structure does not lower $B$ as sharply as $\beta$, thereby favoring centralization.
} 
can be done by choosing task $D$ if and only if $\eta \geq \theta$. What is interesting here is that once the firm makes a commitment, the ex post temptation for the firm totally dissipates: since the worker with the highest output is also the one with the highest ability, the efficient promotion rule turns out to be ex post optimal as well. The commitment to the efficient promotion rule is the almighty solution in this context, which makes each worker's objectives roughly aligned with the firm's objectives and realizes the allocation which maximizes the total output. As this argument indicates, the cost of decentralization in this context depends crucially on how easily the firm can make the commitment credible without any enforcement by a third party. The presence of mutual trust could work as a substitute for legal enforcement by making the commitment feasible at a lower cost, which allows the firm to exploit the role of promotion as an incentive device more effectively. ${ }^{25}$

\subsection{On the productivity dispersion across firms}

In the previous subsection, we have raised several potential determining factors of decentralization. While identifying the determinants of decentralization bears some importance in its own right, it also offers an implication of broader scope as it can shed light on one of the long standing puzzles in economics. It has long been argued that there exists a substantial disparity in labor productivity across firms and countries which cannot easily be explained by observable factors, even after controlling for all conceivable measures of inputs. For instance, Syverson (2004a) shows that plants at the 90th percentile are four times as productive as those in the 10th percentile. Only half of this difference in labor productivity could be accounted for by differences in inputs such as capital intensity. Similar observations have been made by others who by and large find persistent and sizeable differences in labor productivity even within narrowly defined sectors.

While the exact nature of this productivity dispersion still remains largely a puzzle, it has been pointed out recently that variations in management practices can account for a substantial portion of it (Bloom and Van Reenen, 2007, 2010; Bloom et al., 2010). There are two sets of findings that have led to this hypothesis. First, the recent literature indicates that the quality of management can be objectively quantified, and moreover that there is a set of

\footnotetext{
${ }^{25}$ The way trust works here goes both ways. On one hand, to allow for greater job discretion, the firm needs to trust its workers to behave closely in line with its objectives. One the other hand, the workers also need to trust the firm for evaluating them on what they have contributed and, more importantly, not rewarding a worker who deviates from the efficient task choice rule.
} 
"good" management practices, such as well defined targets and performance measures, proper incentive systems and decentralization of authority, which universally contribute significantly to productivity improvements. Second, like productivity performances, there is also a wide dispersion in managerial practices, indicating the coexistence of some well managed firms at one tail of the distribution and some badly managed firms at the other tail. Putting these pieces together, one can argue that the large productivity dispersion is due, at least in part, to variations in the way firms are organized and managed.

The true question that remains is then why there exist firms which continue to adopt poor management practices. To answer this question, we take the stance that even when decentralization is largely beneficial, its costs vary across firms, and it is simply too costly for some firms to decentralize. ${ }^{26}$ More importantly, the cost of decentralization not only varies across firms, but it is also strongly correlated negatively with the firm' productivity: as we have seen, decentralization imposes less cost to high-productivity firms or those closer to the technology frontier. The implied complementarity between the productivity and the quality of management practices can be a powerful force behind the wide dispersion in firm productivity as efficient firms can afford to adopt better management practices and become even more efficient while inefficient firms are virtually trapped with less effective management practices.

\subsection{An application to the academic profession}

The model environment here offers some relevance for many skill-intensive industries where skills or talents - traits that are not easily quantified nor observed - are highly valued. ${ }^{27}$. One such example, which fits this description rather nicely, is the academic profession where signaling undoubtedly plays a critical part. There are several obvious similarities. First, researchers are rewarded mostly through "promotions" to higher ranks or better universities, but there are obviously no specific promotion rules that are tightly contingent on observable output. Second, each employer is naturally more concerned about an applicant's upside potential, especially when she needs to hire young researchers, rather than past achievements.

\footnotetext{
${ }^{26}$ As suggested by Bloom and Van Reenen (2010), an alternative story is that good management practices are partially like a technology which slowly diffuses throughout the economy. Needless to say, our aim here is not to deny this possibility; it is simply to shed light on one aspect, possibly among many others, of this issue.

${ }^{27} \mathrm{An}$ obvious difference is that there are many potential employers competing for researchers in the academic community. While this is an important extension worth serious consideration, the main logic of this paper is expected to survive even if there are multiple employers.
} 
Finally and most importantly, research activities apparently require a high degree of creativity, and it is typically at our discretion to decide how to proceed our own research. The choice we face is often similar to the task choice problem of the current model: some problems may be intellectually stimulating but do not yield much social value while some others may be intellectually dull but are nonetheless more beneficial. The current analysis predicts that in such a situation, researchers, especially young ones, have excessively strong incentives to work on intellectually stimulating problems even when there are other more important problems.

\section{An extension: endogenous effort and promotion bonus}

In the baseline model, we show that the task choice threshold is monotonically decreasing in $b$. The baseline model thus yields no interesting tradeoff regarding the promotion bonus: if it is the firm's choice to set $b$, the threshold is brought closer to the first-best level by setting it as low as possible. This part of the model is not necessarily satisfactory and also counterintuitive, as it implies that the promotion bonus in this context has no positive incentive effect, which stems from the implicit premise that effort is costlessly supplied by the workers. In this section, in order to address this issue, we consider an extension of the baseline model which incorporates an effort choice problem, on top of the task choice problem we have considered thus far, into the model. This extension, while preserving the main insight of the model, allows us to shed light on a novel tradeoff between task and effort choices which is absent in canonical tournament models.

\subsection{The general framework}

We augment the baseline model by introducing two modifications. First, effort is now costly for the workers, and it is their choice to decide how much effort to supply. Second, while we have assumed thus far that the level of the promotion bonus $b$ is determined by outside market conditions and exogenously given, here we consider an alternative scenario and allow the firm to set $b$ freely to induce costly effort from the workers. ${ }^{28}$ For this extension we restrict our attention to the case of decentralization.

More precisely, let $e_{i} \in\{0,1\}$ denotes the effort level chosen by worker $i$. The output

\footnotetext{
${ }^{28}$ Note, however, that whether $b$ is the firm's conscious choice is of secondary importance: the main purpose of this section is to illustrate a tradeoff between task and effort choices, which is present even when $b$ is determined by market forces.
} 
level for worker $i$ is now given by $y_{i} e_{i}$, instead of just $y_{i}$, where $y_{i}$ is determined in the same way as in the baseline model. The sequence of events in this extended model is summarized as follows:

1. Nature draws the ability types $\left(\eta_{1}, \eta_{2}, \ldots, \eta_{n}\right)$.

2. The firm offers the promotion bonus $b$.

3. Each worker chooses which task to perform and how much effort to exert.

4. Upon observing the realized outputs $\left(y_{1}, y_{2}, \ldots, y_{n}\right)$, the firm chooses a worker to promote.

5. The payoffs are realized.

The effort cost is given by $C$, and we assume $\theta>C>\lambda \theta$, i.e., the effort cost is neither too large nor too small. The first inequality $(\theta>C)$ means that it is efficient to induce effort from all workers, given that task choice is also efficient. The second inequality $(C>\lambda \theta)$ is necessary to make the problem relevant because if the effort cost is too small, ex post bargaining is enough to induce effort. Let $c:=\frac{C}{\lambda}$ for normalization.

We first consider the effort choice problem. Note that since the return to exerting effort is weakly increasing in the ability, the effort choice problem can also be characterized by a cutoff $\hat{\eta}_{n}$ such that worker $i$ chooses $e_{i}=1$ if and only if $\eta_{i} \geq \hat{\eta}_{n} \cdot{ }^{29}$ Given this, if a worker chooses not to exert effort, the promotion probability is $\frac{F\left(\hat{\eta}_{n}\right)^{n-1}}{n}$. Worker $i$ then chooses to exert effort if and only if

$$
\max \left\{\eta_{i}+b q_{D}\left(\eta_{i}\right), \theta+b q_{E}\left(\eta_{i}\right)\right\}-c \geq b \frac{F\left(\hat{\eta}_{n}\right)^{n-1}}{n},
$$

where $q_{k}(\eta)$ is the modified promotion probability contingent on the task choice, given that the worker chooses to exert effort. If (4) does not hold, then the task choice problem becomes totally irrelevant: we simply assume for clarity that the worker chooses task $E$ in that case. As this implies that $\bar{\eta}_{n} \geq \hat{\eta}_{n}$ without loss of generality, (4) can be written as

$$
\theta+b q_{E}\left(\eta_{i}\right)-c \geq b \frac{F\left(\hat{\eta}_{n}\right)^{n-1}}{n} .
$$

\footnotetext{
${ }^{29}$ As we will see shortly, all the workers with $\eta_{i} \in\left[0, \bar{\eta}_{n}\right)$ face the same incentives, and there are also other payoff-equivalent equilibria with no cutoff property.
} 
On the other hand, given that $e_{i}=1$, the task choice problem is virtually the same as before: for $\eta_{i} \geq \hat{\eta}_{n}$, worker $i$ chooses task $D$ if and only if

$$
\eta_{i}+b q_{D}\left(\eta_{i}\right) \geq \theta+b q_{E}\left(\eta_{i}\right)
$$

Given the cutoffs $\left(\hat{\eta}_{n}, \bar{\eta}_{n}\right)$, the workers are separated into at most three intervals: (i) those in $\left[\bar{\eta}_{n}, 1\right]$ exert effort and choose task $D$; (ii) those in $\left[\hat{\eta}_{n}, \bar{\eta}_{n}\right)$ exert effort and choose task $E$; and (iii) those in $\left[0, \hat{\eta}_{n}\right)$ exert no effort and choose task $E$. The modified promotion probabilities are then computed as follows:

$$
\begin{gathered}
q_{E}\left(\eta_{i}\right)= \begin{cases}F\left(\bar{\eta}_{n}\right)^{n-1} \sum_{m=0}^{n-1} \frac{(n-1) !}{m !(n-1-m) !} \frac{G^{m}(1-G)^{n-1-m}}{m+1} & \text { for } \eta_{i} \in\left[\hat{\eta}_{n}, 1\right), \\
\frac{F\left(\hat{\eta}_{n}\right)^{n-1}}{n} & \text { for } \eta_{i} \in\left[0, \hat{\eta}_{n}\right),\end{cases} \\
q_{D}\left(\eta_{i}\right)= \begin{cases}F\left(\eta_{i}\right)^{n-1} & \text { for } \eta_{i} \in\left[\bar{\eta}_{n}, 1\right], \\
F\left(\bar{\eta}_{n}\right)^{n-1} & \text { for } \eta_{i} \in\left[\tilde{\mu}\left(\hat{\eta}_{n}, \bar{\eta}_{n}\right), \bar{\eta}_{n}\right) \\
F\left(\hat{\eta}_{n}\right)^{n-1} & \text { for } \eta_{i} \in\left[\mu\left(\hat{\eta}_{n}\right), \tilde{\mu}\left(\hat{\eta}_{n}, \bar{\eta}_{n}\right)\right), \\
0 & \text { for } \eta_{i} \in\left[0, \mu\left(\hat{\eta}_{n}\right)\right),\end{cases}
\end{gathered}
$$

where $G:=\operatorname{prob}\left(\eta_{i} \in\left[\hat{\eta}_{i}, \bar{\eta}_{i}\right) \mid \bar{\eta}_{n}>\eta_{i}\right)$ and $\tilde{\mu}(\hat{\eta}, \bar{\eta}):=\frac{\int_{\hat{\eta}}^{\bar{\eta}} \eta d F}{F(\bar{\eta})-F(\hat{\eta})}$. Define

$$
P\left(\hat{\eta}_{n}, \bar{\eta}_{n}\right):=\sum_{m=0}^{n-1} \frac{(n-1) !}{m !(n-1-m) !} \frac{G^{m}(1-G)^{n-1-m}}{m+1} .
$$

Note that $\lim _{\hat{\eta}_{n} \rightarrow \bar{\eta}_{n}} P\left(\hat{\eta}_{n}, \bar{\eta}_{n}\right)=1, \lim _{\hat{\eta}_{n} \rightarrow 0} P\left(\hat{\eta}_{n}, \bar{\eta}_{n}\right)=\frac{1}{n}$, and $P\left(\hat{\eta}_{n}, \bar{\eta}_{n}\right)>\frac{1}{n}$ for any $\bar{\eta}_{n} \geq$ $\hat{\eta}_{n}>0$. It is also intuitively clear that $P\left(\hat{\eta}_{n}, \bar{\eta}_{n}\right)$ is strictly increasing in $\hat{\eta}_{n}$.

With some algebra, (5) and (6) can be written as follows:

$$
\begin{gathered}
b\left(F\left(\bar{\eta}_{n}\right)^{n-1} P\left(\hat{\eta}_{n}, \bar{\eta}_{n}\right)-\frac{F\left(\hat{\eta}_{n}\right)^{n-1}}{n}\right) \geq c-\theta . \\
b\left(F\left(\eta_{i}\right)^{n-1}-F\left(\bar{\eta}_{n}\right)^{n-1} P\left(\hat{\eta}_{n}, \bar{\eta}_{n}\right)\right) \geq \theta-\eta_{i} .
\end{gathered}
$$

If there exist interior solutions, these conditions must hold with equality at the cutoffs: let $\left(\hat{\eta}_{n}(b), \bar{\eta}_{n}(b)\right)$ denote the equilibrium cutoffs. There are three remarks we would like to make here.

1. (8) implies that task choice continues to be inefficient, i.e., $\theta>\bar{\eta}_{n}$, as long as $P\left(\hat{\eta}_{n}, \bar{\eta}_{n}\right)<$ 1. On the other hand, the efficiency in task choice can be achieved for a positive $b$ when $b$ satisfies

$$
\frac{b(n-1)}{n} F(\theta)^{n-1}=c-\theta
$$


which never happens in the baseline model. In any case, though, the task choice cutoff never goes above $\theta$.

2. (8) also indicates an intriguing interaction between the effort cutoff and the task choice cutoff. A decrease in $\hat{\eta}_{n}$ (an increase in the effort level) decreases $P\left(\hat{\eta}_{n}, \bar{\eta}_{n}\right)$ taking $\bar{\eta}_{n}$ fixed. This raises the incentive to choose task $D$ for the boundary worker with $\eta_{i}=\bar{\eta}$ because the promotion probability $q_{E}$ is now lower, pointing to a tradeoff such that an increase in effort makes task choice less efficient by lowering $\bar{\eta}_{n}$. This is the force which makes the efficiency in task choice attainable even when $b>0$ : in that case, the efficiency in task choice is achieved because low effort (a high effort cutoff) makes the deviation to task $E$ more profitable for the boundary worker.

3. $b=0$ no longer achieves the first-best efficiency because no worker has an incentive to exert effort if $b$ is too small. More precisely, $b$ needs to be at least large enough to satisfy

$$
\frac{b(n-1)}{n} F\left(\bar{\eta}_{n}(b)\right)^{n-1} \geq c-\theta .
$$

If this fails to hold, all workers choose to exert no effort and consequently choose task $E$ in equilibrium. It is evident that (9) does not hold when $b=0$, under the assumption that $c>\theta$.

Finally, the firm's problem is to choose the promotion bonus $b$ to maximize the expected profit, which is defined as

$$
\begin{aligned}
\max _{b} & \theta \int_{\hat{\eta}_{n}(b)}^{\bar{\eta}_{n}(b)} \eta d F+\int_{\bar{\eta}_{n}(b)}^{1} \eta d F-\frac{\lambda}{n(1-\lambda)} b \\
& +\gamma_{n}\left(\mu\left(\hat{\eta}_{n}(b)\right) F\left(\hat{\eta}_{n}(b)\right)^{n}+\tilde{\mu}\left(\hat{\eta}_{n}(b), \bar{\eta}_{n}(b)\right) \int_{\hat{\eta}_{n}(b)}^{\bar{\eta}_{n}(b)} d F_{\eta_{(n)}}+\int_{\bar{\eta}_{n}(b)}^{1} \eta d F_{\eta_{(n)}}\right) .
\end{aligned}
$$

The tradeoff of our focus can be most clearly be seen in the limiting case where $\gamma_{n} \rightarrow 0 .{ }^{30}$ In this case, the first-order condition is obtained as

$$
-\theta \frac{d \hat{\eta}_{n}}{d b}+\left(\theta-\bar{\eta}_{n}\right) f\left(\bar{\eta}_{n}\right) \frac{d \bar{\eta}_{n}}{d b}=\frac{\lambda}{n(1-\lambda)} .
$$

The first term indicates the loss due to a decrease in effort; the second term indicates the gain due to an improvement in task choice. The optimal promotion bonus thus needs to balance these two forces.

\footnotetext{
${ }^{30}$ Note that $\gamma_{n}$ can be arbitrarily small but needs to be strictly positive to maintain the assignment motive.
} 
The general model, with an arbitrary $n$, is exceedingly complicated to fully characterize, but it can be made much more tractable if we restrict our attention to the case with $n=2$. Although this example presents only a special case of the model described above, it contains all the key elements of the extended model and is highly instructive to illuminate the tradeoff of our focus as we will see next.

\subsection{A case with $n=2$}

With $n=2$, it is straightforward to obtain

$$
P(\hat{\eta}, \bar{\eta})=\frac{F(\hat{\eta})+\frac{F(\bar{\eta})-F(\hat{\eta})}{2}}{F(\bar{\eta})}=\frac{F(\hat{\eta})+F(\bar{\eta})}{2 F(\bar{\eta})},
$$

where we suppress the subscript $n$ for the cutoffs for notational simplicity. The cutoffs, if interior solutions exist, are then obtained as

$$
\begin{gathered}
b \frac{F(\bar{\eta}(b))}{2}=c-\theta . \\
b \frac{F(\bar{\eta}(b))-F(\hat{\eta}(b))}{2}=\theta-\bar{\eta} .
\end{gathered}
$$

One can then show that both $\hat{\eta}(b)$ and $\bar{\eta}(b)$ are decreasing in $b$. First, it directly follows from (11) that

$$
\frac{d \bar{\eta}}{d b}=-\frac{F(\bar{\eta})}{b f(\bar{\eta})}<0
$$

Similarly, from (12), we obtain

$$
\frac{F(\bar{\eta})-F(\hat{\eta})+b\left(f(\bar{\eta}) \frac{d \bar{\eta}}{d b}-f(\hat{\eta}) \frac{d \hat{\eta}}{d b}\right)}{2}=-\frac{d \bar{\eta}}{d b}
$$

Substituting (13) into (14) yields

$$
\frac{d \hat{\eta}}{d b}=\frac{1}{b f(\hat{\eta})}\left(F(\bar{\eta})-F(\hat{\eta})-(2+b f(\bar{\eta})) \frac{F(\bar{\eta})}{b f(\bar{\eta})}\right)=-\frac{1}{b f(\hat{\eta})}\left(F(\hat{\eta})+\frac{2 F(\bar{\eta})}{b f(\bar{\eta})}\right)<0 .
$$

The structure of the model is much simpler now, where $\bar{\eta}(b)$ is uniquely pinned down from (11) for a given $b$, and $\hat{\eta}(b)$ is then obtained from (12). As stated, $b$ needs to be sufficiently large for the existence of interior solutions. Since $\theta \geq \bar{\eta} \geq \bar{\eta}$, a necessary condition for interior solutions to exist is

$$
b \geq b_{\min }:=\frac{2(c-\theta)}{F(\theta)}
$$


Note that $\hat{\eta}\left(b_{\min }\right)=\bar{\eta}\left(b_{\min }\right)=\theta$, so that task choice is first-best efficient at $b=b_{\min }$. If $b<b_{\min }$, no worker has an incentive to exert effort and the expected output level is zero. Since the expected profit (per worker) is $-b / 2$, it is strictly better for the firm to offer $b=0$. Then, the optimal promotion bonus is positive if and only if

$$
\int_{\theta}^{1} \eta d F \geq \frac{b_{\min }}{2} \Leftrightarrow \frac{1-\theta^{2}}{2} \geq \frac{2(c-\theta)}{F(\theta)}
$$

The condition holds if $c$ is sufficiently close to $\theta$.

Given this, we can also obtain sharper predictions for the firm's problem. The first-order condition (10) can now be written as

$$
\frac{\theta}{b f(\hat{\eta})}\left(F(\hat{\eta})+\frac{2 F(\bar{\eta})}{b f(\bar{\eta})}\right)-(\theta-\bar{\eta}) \frac{F(\bar{\eta})}{b}=\frac{\lambda}{2(1-\lambda)}
$$

where we maintain that $\gamma_{n} \rightarrow 0$. Suppose that (15) is satisfied and it is optimal for the firm to offer a positive $b$. The firm then raises $b$ above the minimum level to induce more effort, even though it results in more distortion in task choice, if

$$
\frac{\theta}{b_{\min } f(\theta)}\left(F(\theta)+\frac{2 F(\theta)}{b_{\min } f(\theta)}\right)=\frac{\theta F(\theta)}{2(c-\theta) f(\theta)}\left(F(\theta)+\frac{2 F(\theta)^{2}}{2(c-\theta) f(\theta)}\right)>\frac{\lambda}{2(1-\lambda)} .
$$

The condition again holds if $c$ is sufficiently close to $\theta$. The tradeoff faced by the firm is now clear. To see this, note that the efficiency requires $\hat{\eta}=0$ under the maintained assumption. Since $\bar{\eta}\left(b_{\min }\right)=\hat{\eta}\left(b_{\min }\right)=\theta$, an increase in $b$ above $b_{\min }$ improves effort choice but lowers the task choice cutoff away from the first-best level. This is the case when both (10) and (16) hold, in which case the loss of output due to low effort becomes too costly, and the firm hence needs to induce higher effort by raising $b$ even at the expense of more distortion in task choice. $^{31}$

\section{Conclusion}

This paper provides a model where promotion carries two roles - assignment and incentive provision - that often conflict with each other. When the principal is unable to commit to the efficient promotion rule, too many agents are induced to work on the difficult task to signal their productivities. To minimize this loss, the principal may centralize task choices

\footnotetext{
${ }^{31}$ Of course, this distortion could enhance welfare in the presence of information asymmetry when the task choice cutoff moves towards the second-best level.
} 
despite the fact that it necessarily results in inefficient use of private information. The model clarifies the costs and benefits of decentralization and provides several predictions that are in line with recent empirical evidence on firm organization.

\section{Appendix}

Here, we consider the effect of a simultaneous increase in $b$ and $n$ by multiplying them by the same factor, so that the ex ante expected promotion bonus $\frac{b}{n}$ is kept constant. To this end, define the cutoff ability level as a function of $b$ and denote it by $\eta_{n}(b)$. We can then show the following.

Proposition 7 There exists $\bar{\omega}$ such that $\eta_{(1+\omega) n}((1+\omega) b)>\eta_{n}(b)$ for $\omega>\bar{\omega}$. Moreover, $\bar{\omega}=0$ if $n+(n-1) \ln F(\theta)<0$.

Proof: By definition,

$$
\theta-\frac{n-1}{n} b F\left(\eta_{n}(b)\right)^{n-1}=\eta_{n}(b) .
$$

It then suffices to show that

$$
\theta-\frac{(1+\omega) n-1}{(1+\omega) n}(1+\omega) b F\left(\eta_{n}(b)\right)^{(1+\omega) n-1}>\eta_{n}(b),
$$

which can be written as

$$
1>J_{n}(\omega):=\frac{(1+\omega) n-1}{n-1} F\left(\eta_{n}(b)\right)^{\omega n} .
$$

First, since $\lim _{\omega \rightarrow \infty} J_{n}(\omega)=0$, this condition holds when $\omega$ is sufficiently large. Second, $J_{n}$ is strictly decreasing in $\omega$ if

$$
n+((1+\omega) n-1) \ln F\left(\bar{\eta}_{n}(b)\right)<0 .
$$

Since $J_{n}(0)=1, J_{n}(\omega)<1$ for all $\omega>0$ if

$$
n+(n-1) \ln F\left(\bar{\eta}_{n}(b)\right)<n+(n-1) \ln F(\theta)<0 .
$$




\section{References}

Acemoglu, Daron, Philippe Aghion, and Fabrizio Zilibotti, 2006, Distance to Frontier, Selection, and Economic Growth, Journal of the European Economic Association, 4, 37-74.

Acemoglu, Daron, Philippe Aghion, Claire Lelarge, John Van Reenen, and Fabrizio Zilibotti, 2007, Technology, Information, and the Decentralization of the Firm, Quarterly Journal of Economics, 122, 1759-99.

Aghion, Philippe and Jean Tirole, 1997, Formal and Real Authority in Organization, Journal of Political Economy, 105, 1-29.

Aghion, Philippe, Nick Bloom, Richard Blundell, Rachel Griffith, Peter Howitt, 2005, Competition and Innovation: An Inverted-U Relationship, Quarterly Journal of Economics, 120, 701-28.

Alonso, Ricardo, Niko Matouschek, 2007, Relational Delegation, RAND Journal of Economics, 38, 1070-89.

Baker, Geroge P., Michael C. Jensen, and Kevin J. Murphy, 1988, Comepnsation and Incentives: Practice vs. Theory, Journal of Finance, 43, 593-616.

Bernherdt, Dan, 1995, Strategic Promotion and Compensation, Review of Economic Studies, $62,315-39$.

Bloom, Nichilas and John Van Reenen, 2007, Measuring and Explaining Management Practicies across Firms and Countries, Quarterly Journal of Economics, 122, 1341-408.

Bloom, Nicholas and John Van Reenen, 2010, Why Do Management Practices Differ across Firms and Countries, Journal of Economic Perspectives, 24, 203-24.

Bloom, Nicholas and John Van Reenen, 2011, Human Resource Management and Productivity, forthcoming in Handbook of Labor Economics.

Bloom, Nicholas, Raffaella Sadun, and John Van Reenen, 2010, Does Product Market Competition Lead Firms to Decentralize? American Economic Review Papers and Proceedings, $100,434-8$.

Bloom, Nicholas, Raffaella Sadun, and John Van Reenen, 2010, Recent Advances in the Empirics of Organizational Economics, Annual Review of Economics, 2, 105-137. 
Bloom, Nicholas, Raffaella Sadun, and John Van Reenen, 2011, The Organization of Firms across Countries, mimeo.

Bloom, Nicholas, Benn Eifert, Aprajit Mahajan, David McKenzie, and John Roberts, 2011, Does Management Matter? Evidence from India, mimeo.

Blundell, Richard, Rachel Griffith, and John Van Reenen, 1999, Market Share, Market Value and Innovation in a Panel of British Manufacturing Firms, Review of Economic Studies, $66,529-54$.

Bresnahan, Timothy, Erik Brynjolfsson, and Lorin Hitt, 2002, Information Technology, Workplace Organization and the Demand for Skilled Labor: Firm-Level Evidence, Quarterly Journal of Economics, 117, 339-76.

Caroli, Eve and John Van Reenen, 2001, Skill Biased Organizational Change, Quarterly Journal of Economics, 116, 1449-92.

Chen, Kong-Pin, 2003, Sabotage in Promotion Tournaments, Journal of Law, Economics, and Organization, 19, 119-40.

Cunat, Vicente and Maria Guadalupre, 2005, How Does Product Market Competition Shape Incentive Contracts, Journal of the European Economic Association, 3, 1058-82.

Cunat, Vicente and Maria Guadalupre, 2009, Globalization and the Provision of Incentives inside the Firm: the Effect of Foreign Competition, Journal of Labor Economics, 27, $179-212$.

Dessein, Wouter, 2002, Authority and Communication in Organizaitons, Review of Economic Studies, 69, 811-38.

Fairburn, James A. and James M. Malcomson, 2001, Performance, Promotion and the Peter Principal, Review of Economic Studies, 68, 45-66.

Gibbons, Robert and Michael Waldman, 1999a, Careers in Organizations, in Handbool of Labor Economics, Vol. 3, eds. Ashenfelter, Orley and David Card, Amsterdam: NorthHolland.

Gibbons, Robert and Michael Waldman, 1999b, A Theory of Wage and Promotion Dynamics indise Firms, Quarterly Journal of Economics, 114, 1321-58. 
Gibbons, Robert and Michael Waldman, 2006, Enriching a Theory of Wage and Promotion Dynamics inside Firms, Journal of Labor Economics, 24, 59-107.

Golan, Limor, 2005, Counteroffers and Efficiency in Labor Markets with Asymmetric Information, Journal of Labor Economics, 23, 373-93.

Guadalupe, Maria and Julie Wulf, 2010, The Flattening Firm and Product Market Competition: the Effect of Trade Liberalization on Corporate Hierarchies, American Economic Journal: Applied Economics, 2, 105-27.

Guiso, Luigi, Paola Sapienza, and Luigi Zingales, Does Culture Affect Economic Outcomes? Journal of Economic Perspectives, 20, 23-48.

Hart, Oliver, 1983, The Market Mechanism as an Incentive Scheme, Bell Journal of Economics, 14, 366-82.

Ishida, Junichiro, 2004, Signaling and Strategically Delayed Promotion, Labour Economics, $11,687-700$.

Ishida, Junichiro, 2006, Optimal Promotion Policies with the Looking-Glass Effect, Journal of Labor Economics, 24, 857-77.

Ishida, Junichiro, 2012, Dynamically Sabotage-Proof Tournaments, forthcoming in Journal of Labor Economics.

La Porta, Rafael, Florencio Lopez de Silanes, Andrei Shleifer, and Robert Vishny, 1997, Trust in Large Organizations, American Economic Review, 87, 333-8.

Lazear, Edward P., 1989, Pay Equality and Industrial Politics, Journal of Political Economy, $97,561-80$.

Lazear, Edward P. and Sherwin Rosen, 1981, Rank-Order Tournaments as Optimum Labor Contracts, Journal of Political Economy, 89, 841-64.

Malcomson, James M., 1984, Work Incentives, Hierarchy, and Internal Labor Markets, Journal of Political Economy, 92, 486-507.

Nickell, Stephen J., 1996, Competition and Corporate Performance, Journal of Political Economy, 104, 724-46.

Owan, Hideo, 2004, Promotion, Turnover, Earnings, and Firm-Sponsored Training, Journal of Labor Economics, 22, 955-78. 
Prendergast, Canice, 1993, The Role of Promotion in Inducing Specific Human Capital Acquisition, Quarterly Journal of Economics, 108, 523-34.

Rajan, Raghuram G. and Julie Wulf, 2006, The Flattening Firm: Evidence from Panel Data on the Changing Nature of Corporate Hierarchies, Review of Economics and Statistics, $88,759-73$.

Ricart i Costa, Joan, 1988, Managerial Task Assignments and Promotion, Econometrica, 56, 449-66.

Schmidt, Klaus M., 1997, Managerial Incentives and Product Market Competition, Review of Economic Studies, 64, 191-213.

Syverson, Chad, 2004, Market Structure and Productivity: A Concrete Example, Journal of Political Economy, 112, 1181-222.

Waldman, Michael, 1984, Job Assignments, Signalling, and Efficiency, Rand Journal of Economics, 15, 255-67.

Waldman, Michael, 2003, Ex Ante Versus Ex Post Optimal Promotion Rules: The Case of Internal Promotion, Economic Inquiry, 41, 27-41. 


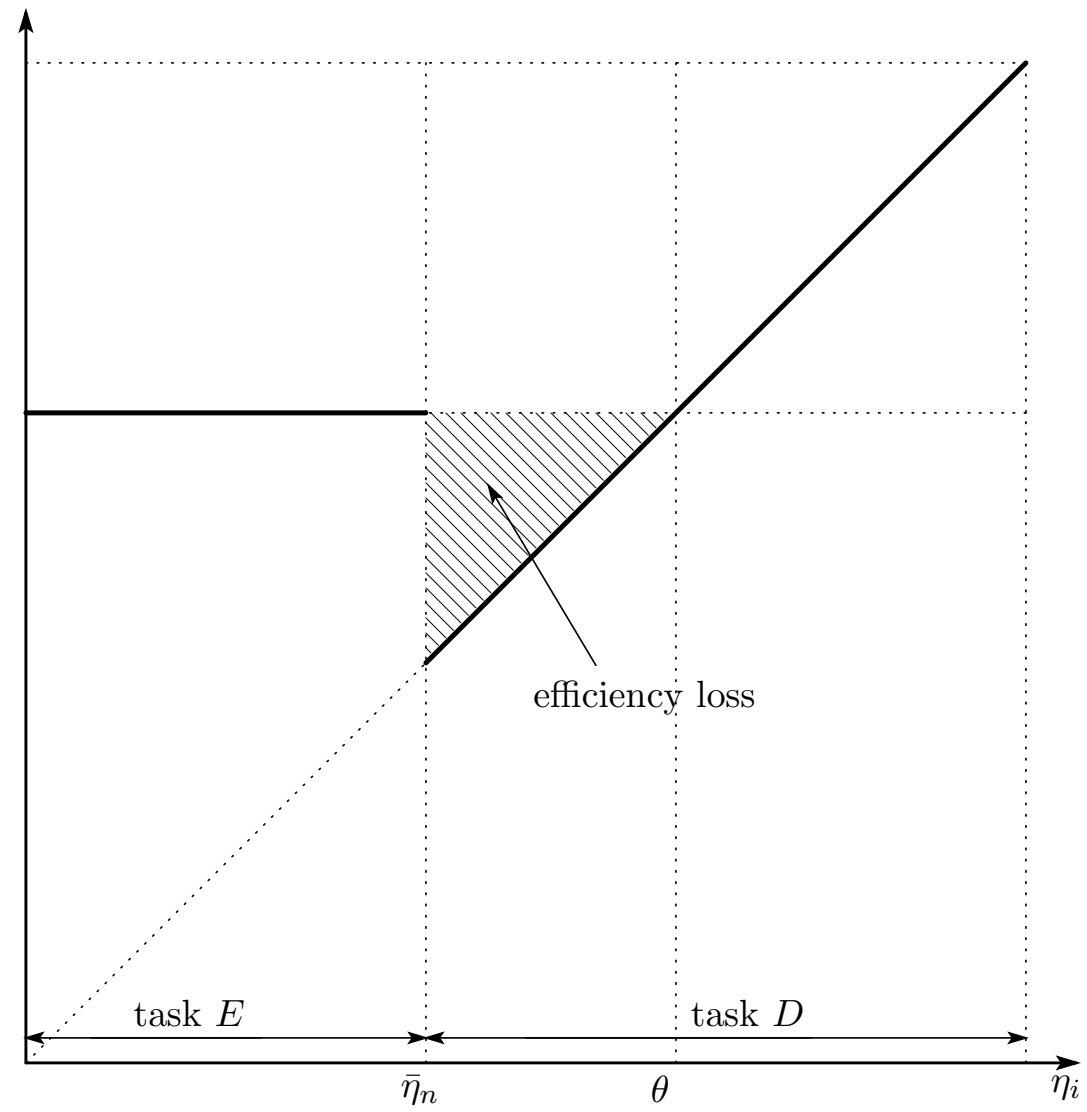

Figure 1: An equilibrium and the output loss. 